\title{
Introduction
}

The healthcare sector has undergone a number of transformations, including the movement away from a paternalistic approach towards patients (i.e. one directed entirely by the doctor) to one that is more patient-centred (Laing et al., 2002). This should have resulted in patients' values, needs and preferences being used to guide clinical decisions in service delivery (Godolphin, 2009; Institute of Medicine, 2001). However, the patient's role remains largely limited to the provision of information (Elg et al., 2012), despite the continuous promotion of this patient centred-care approach in healthcare delivery (Department of Health, 2010; Gill et al., 2011; Taylor, 2009). This is affirmed by research suggesting that two-thirds of the doctor-patient encounters is dominated by the professionals (Collins et al., 2007).

To co-create improved healthcare, patient's active participation is viewed as being important (Gallan et al., 2013; Hausman, 2004; Jaakkola and Halinen, 2006). Hence a change from passive patients to active partners or coproducers (Auh et al., 2007; Wikstrom, 1996) is expected to enhance medical management decisions and outcomes (Flynn et al., 2012; McColl-Kennedy et al., 2012). There is therefore a need for more research to gain a better understanding of how interdependence in the doctor-patient dyad can be seen as a resource that can be managed and exploited for value co-creation (Aarikka-Stenroos and Jaakkola, 2012; Lin and Hsieh, 2011; Saarijarvi et al., 2013). This study responds to this call by researchers to further explore value co-creation from the dyadic perspective at the micro level.

Addressing this gap, the objectives of this study are three-fold. Firstly, the study seeks to understand how the focal dyad consisting of the doctor and the 
patient defines value in the healthcare setting. Secondly, it examines these actors' experiences in the consulting room and identifies the critical areas that influence the co-creation process between the focal dyad at the micro level. Finally, a model of the doctor-patient dyadic value co-creation process in healthcare service delivery is proposed.

The paper is structured as follows. The next section reviews the literature starting with the definition of value. This is followed by a brief review of service experience and the value co-creation process in general perspective and its linkage to the healthcare service. The subsequent sections present the methodology employed in the study, followed by the findings on the value perspectives and co-creating processes of the focal dyad in healthcare service delivery at the micro level, and finally, present the theoretical and practical implications for researchers and practitioners within the healthcare sector.

\section{Defining Value}

Value has been the prime concern of many in the marketing and service management literature (Gummesson et al., 2010; Voima et al., 2010). Although the value concept has received much credence from both practice and academia, it still remains difficult to define, measure and understand (Geraerdts, 2012). Value is conceptualised as the actors' "perceived trade-off between benefits and sacrifices within relationships" (Blocker, 2011, p. 534). In healthcare, value has been defined as health outcomes achieved relative to cost (Porter, 2009, 2010). This aligns with the economic dimensions of value, and since healthcare differs from traditional business sectors (Young and 
McClean, 2008); it may be more appropriate for value to be examined from the experiential perspective (Zainuddin et al., 2011). Holbrook (2006a) explained that value could emerge through a variety of consumer experiences, described as "interactive relativistic preference experience" (Holbrook, 2006b, p.212).

Mathwick et al. (2001) opined that when the consumption experience of a service is rich in value, it impacts on the relativistic preferences possessed by the actors involved. This suggests that value offers both extrinsic and intrinsic benefits to the actors in the service encounter (Mano and Oliver, 1993). This also reflects the multidimensionality (Sanchez-Fernandez and Iniesta-Bonillo, 2007), subjectivity (Cova et al., 2011; Helkkula et al., 2012), and context specificity (Chandler and Vargo, 2011) of value. The subjectivity of value in this case extends the difficulties and complexities in ascertaining whether or not value has been achieved. Hence, understanding what kind of value is created, and how it is generated is critical in the value co-creation process (Saarijarvi et al., 2013), which also differs depending on the context (Vargo and Lusch, 2008). This study adopts the experiential perspective of value, defined as "a consumer's perceptual and relative preference for services arising from the individual's interaction with a consumption setting that facilitates or blocks achievement of their goals or purposes" (Andrews et al., 2007, p. 642).

\section{Experiences and the co-creation process}

Value co-creation refers to the processes through which the providers collaboratively engage with customers to create value (Prahalad and Ramaswamy, 2004). Co-creation is not considered a new concept (Ind and 
Coates, 2013), however, the emergence of service-dominant logic (Vargo and Lusch, 2004) had shed more light on the concept as an appropriate mechanism of creating value. It is argued that, "value is always uniquely and phenomenologically determined by the beneficiary" (Vargo and Lusch, 2008, p. 7), however, its creation is influenced by the processes of the service encounter between the actors (Gronroos, 2011; Heinonen et al., 2010). Hence, effective co-creation in the encounter may lead to value creation, whereas ineffective integration of actor resources could lead to value destruction (Echeverri and Skalen, 2011; Ple and Caceres, 2010).

Gummerus (2013) opines that, customer value creation is centred on what the customer does, whereas co-creation takes into perspective the processes within the network. It can be argued that, the actors' continuous participation in the value co-creation process is largely influenced by their experiences, both past and present (Gentile et al., 2007; Payne et al., 2008). These experiences could be at the cognitive and subconscious level leading to knowledge growth through interactive processes (Tsai, 2005). Hence creating a superior patient experience is considered key in the value co-creation process (Helkkula et al., 2012; Sandstrom et al., 2008; Spena et al., 2012).

These experiences are influenced by the social context within which the encounter takes place (Edvardsson et al., 2011). Interactions within the focal dyad drive the service exchange (Ballantyne and Varey, 2006), which is also considered as one of the focal points in the co-creation process (Flint, 2006; Gronroos, 2006). This is also influenced by the actors' social skills, which afford them the opportunity to communicate with each other and create an enabling environment for the service exchange (Lin and Hsieh, 2011). The 
social context also provides the platform for actors to exhibit their capabilities and competencies. Donna and Novak (1997) pointed out that these competencies help create a balance between their social skills and the challenges of their interactions. These competencies (driven by knowledge) are considered as key resources in the value co-creation process (Gummesson et al., 2010; Nambisan and Nambisan, 2009; Schau et al., 2009; Zwick et al., 2008). The social context therefore, greatly impacts on the service exchange and the co-creation process (Edvardsson et al., 2011).

Actor experiences are also influenced by their beliefs and perceptions (Gentile et al., 2007), which are essential in the value co-creation process (Payne et al., 2008; Vargo et al., 2008). The beliefs and perceptions of the actors drive their emotional appeal (Higgins et al., 1992; Sandstrom et al., 2008) as well as their level of trust and assurances that impact on the co-creation process (McKnight et al., 1998; Ranganathan et al., 2013). In this respect, creating a customer experience in a service encounter depends more on the relationship between the actors and not about the product per se (Payne et al., 2008).

Prominent to the value co-creation process is the level of partnership between the actors (Jaakkola and Alexander, 2014). Partnership requires both actors to understand each other and provide greater clarification about their respective roles and responsibilities (Austin and Seitanidi, 2012; Hennig-Thurau, 2004). Austin and Seitanidi (2012) opined that the dynamics of the value creation process changes as the relationship between partners evolves. Seitanidi (2008) further explained that, partnership requires actors to adapt responsibilities that depart from their limiting predefined roles. This allows for 
active participation or involvement and orientation of the actors in the consultation process (Claramita et al., 2011; Makaoul and Clayman, 2006). The extant literature suggests patients who are actively involved in the consultation resulting from the actor partnership are likely to comply with the providers' advice (Godolphin, 2009), which is also regarded as an essential role of the patient (Dellande et al., 2004). Hence the need for actor partnership in the value co-creation process is critical, improving on actor involvement, cooperation and empowerment (Gill et al., 2011; McColl-Kennedy et al., 2012).

As social practices are intrinsic to healthcare service provision, value creation is dependent on the involvement of actors (Gronroos and Voima, 2013). However, the application of value co-creation in the context of healthcare raises a number of questions yet to be answered in the literature. For instance; does value co-creation result merely from the interactions between the doctor and the patient? How is value co-creation in healthcare modelled from the dyadic perspective of the doctor and the patient? The extant literature suggests a limited understanding of the value co-creation processes in healthcare and other service sectors from the dyadic perspective (Aarikka-Stenroos and Jaakkola, 2012; Lin and Hsieh, 2011). However, models developed by Nambisan and Nambisan (2009) and McColl-Kennedy et al. (2012) provide good insights of contributing to the concept of value co-creation in the healthcare setting but investigating from the dyadic perspective at the micro level requires further research. This study therefore examines the interdependence of the doctor and patient and how this is managed as a resource in co-creating value at the micro level. 


\section{Methodology}

To examine the value co-creation processes in the healthcare setting within the focal dyad (doctors and outpatients), face-to-face interviews were conducted employing the critical incident technique (CIT) (Flanagan, 1954). Flanagan (1954, p. 327) defined CIT as "a set of procedures for collecting direct observations of human behaviour in such a way as to facilitate the potential usefulness in solving practical problems and developing broad psychological principles". Also, Bitner et al. (1990) saw CIT as being essentially a classification technique that employs analysis of stories or critical incidents. The method is particularly useful when a thorough understanding of an activity or phenomena is required in exploratory research (Grove and Fisk, 1997; Keatinge, 2002) aimed at identifying relevant issues that have not been addressed in previous research (Gremler, 2004). By employing this research method, the study aimed to examine the actor experiences in the consulting room to understand the value co-creation processes at the micro level, following the procedures outlined by Flanagan (1954).

To achieve this aim, a purposive sampling method was employed to select 8 doctors and 24 outpatients who were interviewed from two hospitals in Accra, Ghana. The specific doctors were selected because they were dealing with outpatients rather than inpatients. This meant that the consultations tended to be on a one to one basis rather than the case of inpatients where a group of health professionals may be involved in the service encounter. Respondents were interviewed after receiving ethical approval from the author's academic institution and the health authorities in Ghana. Considering the dyadic nature of the study, doctors were first recruited and interviewed, followed by interviewing 
three outpatients seen by each doctor. On average, each interview lasted about 45 minutes.

Respondents were asked to recall and describe, whether favourable or unfavourable;

$\checkmark$ Situations where the doctor-patient encounter affected their experience of the service;

$\checkmark$ Elaborate on the reasons why that happened;

$\checkmark$ How they handled or managed the incident;

$\checkmark$ How the incident affected their experience, perception and value outcome of the service delivery.

A respondent's ability to recall incidents about their past experiences during the service encounter having direct impact on the value creating processes and service outcome was considered as critical (Roos, 2002). Flanagan (1954, p. 327) clarified 'critical incident' as "incident that occur where the intent of the act seems fairly clear to the observer and where its consequences are sufficiently definite to leave little doubt concerning its effects". The interviews were audio-recorded with the permission of the interviewees and subsequently transcribed. Data was ordered into relevant categories following a classification scheme developed by the authors. In all 76 useable critical incidents were recorded, which is considered adequate, as 50-100 critical incidents are considered appropriate for an exploratory study of this nature (Flanagan, 1954). The CIT method was pre-tested prior to the main study interviewing two outpatients and one doctor.

The abductive reasoning approach was followed in analysing the data (Dubois and Gadde, 2002) with the aim of understanding and interpreting the experiences that influence the value co-creation process within the healthcare 
service. Thematic analysis was used by ascribing meanings to the incidents and codifying these incidents into categories and sub-categories (e.g. Gummerus and Pihlstrom, 2011). The sorting of the incidents resulted in three (3) main categories which were labelled as: (a) social context, (b) beliefs and perception, and (c) partnership, to address the concept of value co-creation process in the healthcare service context as presented in table 1.

In assessing the reliability and validity of the data, the incidents were subjected to the categorisation process by two independent judges. Following Perreault and Leigh (1989), the index of reliability $\left(\mathbf{I}_{\mathbf{r}}\right)$ obtained from the inter-judge categorisation was .89 and .86 for the favourable and unfavourable incidents respectively. This index of reliability takes into account the reliability of the whole coding process and not merely contrasting the level of agreement between judges. Perreault and Leigh (1989) suggest that, in exploratory studies, $I_{r}$ of .70 is considered acceptable.

In addition to the reliability already established, validity of the data was assessed. In line with Maxwell's (1992) validity measures, copies of transcripts with initial categories were sent to three respective respondents (one doctor and two patients), giving them the opportunity to cross check the categories against their experiences reported in the interviews. This process confirms the soundness of the categories mirroring the individual participant experiences (Butterfield et al., 2005; Whittemore et al., 2001). Again, the measures outlined by Flanagan (1954) to enhance the validity of the data were strictly followed throughout the interview process and the classification of the categories. 


\section{Findings}

This section analyses the results making reference to the categories and subcategories classified in table 1 . The value perspectives and outcomes are addressed. The value co-creation processes between the doctor and the outpatient during the service encounter, taking into consideration their favourable and unfavourable experiences are also outlined.

\section{Table 1: Main and subcategories of the value co-creating processes of the focal dyad}

Insert table 1 here

\section{Value perceptions and outcomes in healthcare}

Actors in the service encounter have a different set of goals that translate into the value that is determined at the end of the encounter. Individuals depending on their expectations mostly perceive value differently. For value to be cocreated, there is a need to understand how the focal dyad perceive value in the healthcare setting. Respondents were asked about what they consider as value in receiving or delivering healthcare. From the research, both actors expressed similar views as regards to what they consider as value in the care that is delivered and received.

I expect to get the best of care from the doctor and ultimately get well as soon as possible. For me I think that is the value I receive from the 
service, if I get well at the end of the day, then I'm okay then I know that my expectations have been met. [39-year-old patient]

I think basically what I consider as value is seeing the patient getting well. [Doctor $M_{1}$ ]

However, some patients considered value as experiences culminating from the consulting room through to taking their drugs and getting well. All patients interviewed considered getting well as the value achieved from seeking healthcare, however, some argued that, 'getting well' was only part of the value that is determined. Some patients considered their involvement in consultations as being critical to what they consider as value, hence, they regard value as not being achieved when their participation is denied, even though they get well after taking their medication. On the other side of the dyad, in addition to seeing the patient getting well the doctors also considered other factors. They considered value as pertaining to having all functional units in the hospital working and ultimately being able to understand the problems presented by the patients, get the right diagnosis, and prescribe the right drugs.

For me, I expect that all relevant units within the hospital are working, then the right diagnosis is made, right drugs prescribed, I expect the patient to comply, and when the patient gets well, then I will say I have achieved value for the time spent with the patient. [Doctor $F_{3}$ ]

Combining both perspectives, value in healthcare can be said to be attributed to; patient getting well, receiving the best of care, involvement in the decisionmaking process, positive experience in the consulting room, understanding the patient, making the correct diagnosis, prescribing the right drugs, the patient complying to directives, seeing patient happy and satisfied, and ensuring functional units are working. 
The research also revealed how the value co-creation process improves the service outcome. When asked about the net effects of their experiences in the consulting room on the value outcomes and how this could be improved, both expressed the need to enhance the level of engagement in the consulting room, which would lead to positive experiences. They explained positive outcomes to include; improved service engagement, positive experiences, improved compliance, recognition of the patient as part of the condition management process, reduced complications and repeat visits, and improved wellbeing.

I think if the doctor better understands me and creates an enabling environment, then this will lead to better engagement and an understanding of each other in the consulting room...so we both have responsibilities to play to ensure a better outcome... this will more likely speed up the healing process...[30-year-old patient]

Its important for patients to understand their roles... also empowering the patient is a step in the right direction so they can better manage their condition leading to positive outcomes... hence reducing the tendency of repeat complications, but rather improved well being ...[Doctor $\left.M_{1}\right]$

The focal dyad noted the importance of positive experiences in the consulting room in shaping the service outcome resulting from the value co-creation process. Knowledge of the value perceptions of the actors provides the basis of understanding the co-creation process of the focal dyad at the micro level, as addressed in the following section.

\section{Actors experiences and value co-creation process}

\section{Social context}

Both actors revealed the effects of the social context on their experience in the consulting room in relation to the value co-creation process. Three main 
elements constituting the social context impacting on their experiences included the doctors' social skills, the level of interactions between the actors and their knowledge and competences.

In relation to the doctors' social skills, the findings revealed the importance of this attribute in the value co-creation process between the actors in the consulting room. These skills included the actors' interpersonal skills, friendliness, empathy and respect for the patient.

The doctor was very friendly and nice and I think she has good interpersonal skills and she really used that to create a very conducive environment that encouraged me to freely and actively participate in the consultation and therefore, get the best out of it... [35-year-old patient]

Establishing a good rapport with the patient is critical... this helps break their silence and tells you everything, because some of them actually decide what to tell you based on your attitude... [Doctor $F_{1}$ ]

Mutual Respect was also considered to be important between the actors in the service encounter.

Respecting the patient's views is very important as it encourages the patient to share more information with you, he/she is not scared or afraid to say anything because they believe their views are respected and welcomed. The patients I see accord me the needed respect and it is important that I also respect them. [Doctor $M_{2}$ ]

As part of the value creation process, doctors are expected to relate to, respect, empathise, and build a conducive environment with their patients. Both actors pointed out situations where the lack of these characteristics negatively impacts on the service encounter.

The respondents also emphasised the importance of the nature of interaction during the consultation process. This encompassed an emphasis on listening, explaining, non-assertive response and a demonstration of understanding. 
I attended to some patients who appeared very nervous... such patients are usually afraid to say what is on their mind and that makes the consultation quite difficult... They barely participate in the interaction... [Doctor $\mathrm{M}_{2}$ ]

I visited a doctor three months ago in this hospital...he was not engaging... little or no interaction, I reported what was wrong with me and he just listened and prescribed something for me...though it is not strange, but I don't like that and sometimes I feel I did not get value from the time spent... [31-year-old patient]

...Also there are some patients who want to rush and go back to work... for such patients you try to explain issues to them and you realise sometimes their mind is not really there... it rather affects the level of interaction when it happens like that... [Doctor $F_{2}$ ]

Both actors reported favourable and unfavourable experiences during the encounter with regard to the level of interaction between them. The results revealed both similar and contrasting findings from the actors. While some patients complained of lack of engagement from doctors, some doctors also complained about similar behaviour from patients

It is argued that the interaction process affords the patient the opportunity to actively participate in the consultation. Likewise it gives the doctor a greater opportunity to obtain as much information as possible to aid in diagnosing the problem presented. Both actors also agreed that there was a need for two-way communication during the service encounter rather than simply a question and answer session.

... Then the doctor said, 'I expect you to tell me everything I need to hear and feel free to ask questions and say whatever is on my mind'. So I told her everything regarding my condition and she asked me questions and I responded, then it became more like a conversation. She was more engaging and it was great... [29-year-old patient] 
In effect, a doctor's misconception about the patient's problem during the interaction process could result in a wrong diagnosis, which could be detrimental to the patient. Likewise, the patients misunderstanding of the doctor could result in a general assertion that, the doctor is not engaging and caring (Laing et al., 2002).

The data also revealed the contrasting effects of knowledge in the value cocreation process between the actors. The data revealed a high number of unfavourable experiences that resulted mainly from the patients' demonstration of knowledge during the consultation process as shown in table 1 . This could also reflect the upsurge of consumerism in healthcare with patients having developed the habit of making requests as well as pre-empting the diagnosis in some cases. This approach brings out contrasting views from both patients and doctors, while some patients find this normal; some doctors believe this attitude should not be encouraged in healthcare delivery. Some doctors consider it a challenge for which they need to improve their communication skills.

...So I asked the doctor to prescribe a particular drug for me so I can get it from the pharmacy, and he got angry with me - why I should ask him to prescribe that particular drug for me? I was actually surprised because he was so nice before I made the request... [25-year-old patient]

There are some patients who come to the consulting room and actually tell you what they think the diagnosis is and even request specific drugs to be prescribed for them. That is something I think should stop... I don't like that attitude and it sometimes puts me off... [Doctor $M_{5}$ ]

Doctors recognize the fact that there are a number of sources available to the patient, and are therefore not surprised at the changes in patients' attitudes in 
the consulting room. Despite this tension, both doctors and patients generally argued that the final decision rests on the professional judgement of the doctor.

\section{Beliefs and Perceptions}

The behaviours and attitudes of patients and providers are mostly driven by their beliefs and perceptions, which also influence their experiences in the service encounter and the value co-creation process. This also stems from the experiences derived from the social context of the service encounter. The data revealed emotions, trust and assurance as elements of the actors' beliefs and perceptions that directly impacted on their experiences.

Both actors considered the importance of the service encounter and how it impacts on their emotional appeal especially in the case of the patients. From the data, it is worth noting that some patients' treatment processes were greatly influenced by the emotions created by the encounter.

Also the doctor's approach in the consulting room made me feel very comfortable, which really had a positive effect on my experience of the service. I'm emotionally and mentally satisfied when it happens like that, and I believe it helps me in the healing process...for me it's not all about the drugs I receive, but the emotional aspect of the consultation is very important... [58-year-old patient]

Sometimes you meet patients who after the consultation tell you they are fine, and that how you handled their case has given them a reason to believe they are healed. So that also gives me as a doctor some positive feedback right there in the consulting room, which is a good experience for me. [Doctor $M_{3}$ ]

The encouragement I received from the doctor was stimulating and I feel psychologically I was healed... But when things don't go as expected, the treatment is prolonged even though I take the drugs prescribed... I have experienced this a couple of times. [41-year-old patient] 
The focal dyad also noted that the emotional component of the service experience during the encounter could create an affective relationship between them. For instance, a patient had a bad encounter with a doctor and as a result walked out from the consulting room and joined the queue again to see a different doctor in the same hospital, she said:

... So the doctor was really shocked to hear all that transpired between the other doctor and I, and he even said, it's okay, he's sorry for all that has happened, I was touched and felt emotionally satisfied because that was the first time I was meeting that doctor and he was so sensitive to my condition... [A 43-year old patient]

Both doctors and patients expressed the importance of positive experiences in the consulting room to the service delivery and its possible outcomes. For instance, patients were generally happy with doctors who were considerate, understanding and empathetic towards their condition, and negative experiences were reported in cases where opportunities to participate in the consultation were denied.

The data also revealed the importance of the level of trust and assurance in the consultation process, which also results from the level of relationship between the two actors. It was evident from the interviews that trust affects the patient in the value co-creation process.

...But I freely shared information with him simply because I trusted him which resulted from the service and care I received from the doctor. [47year-old patient]

...They wanted to find out if I'm competent and a doctor they can trust. So if I had got any of their questions wrong, they would not have come to me again... I think it's natural that if you trust somebody, you are at peace with him/her, you can freely discuss issues and you have the belief that, that person will not let you down... I consider it valuable [Doctor $\mathrm{M}_{2}$ ] 
...Two months ago, I came here to see a doctor and the assurance he gave me allayed my fears and I begun to feel better long before I left the consulting room... so it's not all about the drugs he prescribes for me but I find these assurances more valuable during the consultation... [44year-old patient]

The focal dyad noted that assurances from the doctor to the patient in relation to their health issues helped in managing their condition leading to value creation. This sometimes allays the fears of the patient depending on the condition that they have. Once the patient is assured of the effectiveness of the service this impacts on the outcome of the service. Likewise, the assurances received by the doctors from the patients in relation to managing their condition also give them a cause to believe there is value in the service delivered.

\section{Partnership}

Partnership between the patient and the doctor consider ways that patients could be empowered in order to engage well in the value co-creation process. This requires active participation and understanding of the actors in the encounter. The data revealed good partnership between the dyad require actor involvement (including the decision-making process), provider-patient orientation, and patient compliance that impact on the value co-creation process.

In relation to actor involvement in the service encounter, the data revealed this is widely initiated by the doctor. The patients maintain that most of them were not involved in the consultation, as they were mainly required to report symptoms. This approach departs from the concept of partnership between the actors in the service encounter. The focal dyad reported different approaches to engagement in relation to actor involvement in the consultation process. The 
data revealed these styles to include the paternalistic approach, shareddecision making and professional-as-agent (Thompson, 2007).

The paternalistic approach is considered to be the traditional consultation model whereby patient involvement in the consultation is limited to reporting symptoms and not being engaged throughout the consultation. Though considered outmoded, it is not uncommon to experience this kind of practice in the healthcare sector, in which case the doctor is seen to dominate the consultation. From the research, some doctors claim to believe and practice a patient-centeredness care approach, however, they do demonstrate this in their actions.

No, I don't involve patients when prescribing. I prescribe after listening to them and asking them a series of questions relevant to their condition. So I prescribe and give the folder back to them to be taken to the pharmacy... Sometimes I do discuss the diagnoses with them, other times I don't. Some of the patients do not really bother to know what the diagnosis is, and all they care is what is given to them to take and get well. [Doctor $F_{2}$ ]

They argue that, the patient does not bother much about their diagnosis, but are more concerned about what is prescribed, this is supported by some of the patients.

I was not involved in the decision making, she did not discuss the diagnosis and the prescription with me, but I think she is the expert and therefore, whatever she gives me is the best for my condition. [A 39year old patient]

Both parties attribute their position to the fact that the doctor is the expert and has the right to exercise their specialised knowledge to make informed decisions regarding the management of the patient's condition. Some of the patients interviewed also considered this practice as the norm since they had 
never experienced a doctor who would involve them in the decision-making process.

Though patients may accept whatever the doctor prescribes, they also believe involving them in the decision-making process may be better. Contrary to the views of some doctors who limit the patient to just providing information, some doctors consider the patient involvement in the decision-making process as something worth doing. Some patients who were delighted that their views were valued also shared this remark.

...as a family physician one of the ways of managing the patient is to reach common ground, so reaching common ground is between you and the patient, I want to write this medicine for you... So I always involve the patient and discuss with them what I'm prescribing and this is when some of the patients make their requests and demands. [Doctor $\left.F_{1}\right]$

I was actively involved in the consultation from start to finish, I was offered the opportunity to suggest options... this was my first experience and it's something I really cherished...this also gives me some sense of responsibility in managing my condition... [50-year-old patient]

This approach is considered very important by the focal dyad in the healthcare service delivery, which affects the patient positively. Specifically, the shared decision model empowers patients to exercise an informed choice and make suggestions to influence the decision in line with what is prescribed. This approach also instils some level of responsibility on the part of the patient in managing their condition, which is paramount in the value co-creation process. The extended form of the shared decision-making model of the consultation is the professional-as-agent where patients' preferences and expectations are incorporated into the decision-making. 
The research also revealed the need to improve on the provider-patient orientation, which is critical in the consultation process. From the research, both patients and doctors call for the need to understand and cooperate with each other to reduce the tendency of value conflict. Considering the different aspirations of the dyad, a better orientation is expected from both actors, which could bring changes in the practice approach to impact on the service outcome.

I think doctors must cooperate with me as a patient and appreciate my expectations and needs of the service I seek...it's not all about the prescription, but I desire to contribute to the consultation...[A 32-year old patient]

Having a good orientation of the patient gives me a fair idea of what is happening, and how to approach different patients with different needs and expectations... for instance, I don't have any problem with patients who come with their own requests and demands, at the end of the day we have to agree on something and it is my duty as the professional to explain issues with the patient for them to understand clearly and as well accept the position taken... [Doctor $M_{4}$ ]

In effect, the provider-patient orientation provides a learning phase for doctors to better comprehend and share the expectations of their patients.

Another important element of the actor partnership revealed in the data is patient compliance to instructions. Patient compliance in healthcare has been a major concern to improving healthcare outcomes. Patient non-compliance is considered to be more attitudinal and behavioural than any other factor.

For me I think it's got to do with the individual's behaviour, for instance I receive all the care I expect to have received, yet I do forget sometimes for no apparent reason, so it's purely personal. I have the drugs, so what other excuse do I have... [26-year-old patient] 
Considering value co-creation in healthcare, this is considered as value-in-use. From the data, both patients and doctors consider the important role compliance plays in service delivery in relation to the patient getting well, and also consider it as the role of the patient. However, as compliance remains a problem in healthcare, doctors are faced with this challenge every day.

There have been a number of times when I had to turn out some patients from my consulting room because they did not adhere to my directives. Some of these patients come back to me for review and you see their conditions deteriorating, and later find out that they did not take their medications as prescribed. It's a serious problem and I'm always harsh on such patients. [Doctor $F_{3}$ ]

Both actors considered the relevance of complying with the medications prescribed and the fact that, patients need to comply in order to get well and achieve the purpose for which they attended the hospital. Once value is achieved through value-in-use, then both doctors and patients can be satisfied with the value they have jointly created.

The model in figure 1 illustrates the value co-creation process of the focal dyad as presented in our findings.

Figure 1: Model of Doctor-Patient dyadic value co-creation process in healthcare

Insert figure 1 here 


\section{Discussion}

The study aimed to understand and examine the actors' (doctors and patients) value perceptions and experiences in the consulting room to further the understanding of value co-creation processes at the micro level. The findings affirm Heinonen et al.'s (2010) assertion that positions the patient as the central focus of the healthcare service without which value is not created. However, the actors' perception of value in healthcare is subjective as evidenced in the findings. The value perceptions outlined by the focal dyad extends beyond Porter's (2010) economic view to the experiential value perspective. This paper posits that value in healthcare is primarily self-oriented that is driven by the actors' experiences, emotions and functional attributes. Hence, value in healthcare should be conceptualised from the experiential perspective (Mathwick et al., 2001), which requires active collaborative behaviours of the provider and the patient. The perception of value and its antecedents implies that the actors (doctors and patients) share different views in co-creating value in healthcare. For instance, the findings suggest that patients do not only consider 'getting well' as value received from the service, but their experiences in the consulting room as well. Hence, the patients' value perceptions are linked to their experiences in the consulting room (hedonic value), whereas doctors consider the functional (utilitarian) value. In effect, there are a number of attributes that impacts on the process as outlined in our conceptualisation, and also confirm that the value perceptions of the actors influence the overall value created. 
The model in figure 1 provides insights into the co-creation process in the dyad and its impact on the service outcome, which stems from the actors' experiences. The dual effects examined in this study also differentiate it from previous studies. The study identified three critical areas of the value cocreation process at the micro level that stemmed from their experiences. These include the social context within which the encounter takes place, the beliefs and perception of the actors, and the partnership between the actors. These require deeper reflection to ascertain how they influence the dyadic value cocreation process and the overall service outcome. From the findings, it is evident that the value co-creation process of the focal dyad (doctor and patient) is fuelled by the experiences of the actors in the consulting room. The study contributes to the value co-creation literature suggesting that; the critical areas of the process identified influence co-creation at the micro level. This also provides clarity in understanding how the interdependence of the two actors could be managed as a resource in the value co-creation process at the micro level. The anticipated activities addressed at the micro-level seek to improve on the service encounter between the doctor and the patient leading to improved service outcomes. This also builds on Gill et al.'s (2011) study and extends their findings to the micro level by examining the effects of the actors' experiences in the value co-creation process.

From figure1, it is noted that there are a number of processes that must be acknowledged by the focal dyad in order to co-create the expected value. Healthcare service delivery is considered a knowledge intensive service whereby the level of doctor's expertise outweighs that of the patient (Jaakkola and Halinen, 2006). This knowledge asymmetry poses a problem in 
appreciating the value co-creation process within the service. Conversely, the advent of consumerism in healthcare (Nettleton, 1995) has seen patients becoming more knowledgeable and informed as a result of access to valuable information in relation to their health needs. This coupled with their experiences enables the patient to convert their "tacit experiential knowledge into explicit knowledge" (Nambisan and Nambisan, 2009, p. 346), which also influences their inputs in the consultation process through information sharing (Gallan et al., 2013). This approach has led to practices engaged by the patient, which some providers in the healthcare sector find difficult to accept.

The effect of knowledge on the actors' experiences in the consulting room is evident in this study, in which case negative experiences reported outnumbered that of the positive experiences. This presents evidence of knowledge conflict between the actors in the service encounter, which can also lead to value destruction (Echeverri and Skalen, 2011; Ple and Caceres, 2010) rather than value creation. In effect, if the overall experience does not satisfy the expectations of the patient, then value is not created. Ple and Caceres (2010, p. 434) argued that the "co-destruction process results in value-codestruction-through-misuse". However, the current study contends that, the codestruction process does not only result from the misuse of these resources. The findings suggest that patients' acquisition of knowledge and demand for a specific request is not completely out of place, especially in an era promoting patient autonomy (Taylor, 2009). However, it appears doctors are not particularly used to such behaviours, resulting in knowledge conflict between the actors. This conflict adversely affects the actors' experiences resulting in possible value co-destruction. Hence, as knowledge is considered one of the 
fundamental resources of value co-creation (Vargo and Lusch, 2004), it will be beneficial for actors to understand each other and accept the changing trends especially in the case of informed and enlightened patients.

The study concludes that the value co-creation process between the focal dyad of the doctor and the patient is driven by their experiences in the consulting room. This calls for the need for both actors to understand each other and engage in a way that would lead to positive experiences. Hence contributing to the S-D logic literature, we affirm that actors co-create value in the service experience (Helkkula et al., 2012). In effect, value creation does not result merely from the interactions between the actors, but require the consideration of other attributes to better understand the interdependences between the actors as outlined. Therefore, the need to consider the social context of the service encounter, the beliefs and perception of the actors, and the actors' partnership is imperative in the value co-creation process.

\section{Managerial implications}

The study suggests that there is the need to promote and practice a patientcentred care approach in delivering care and considered as partners. However, there seems to be limitations in positioning healthcare as patient-led in practice considering the over-dominance of the professional (Collins et al., 2007). The model provides insights into the service engagement processes between the healthcare provider and the patient. There is therefore a need for providers to adopt approaches that allow for better engagement with patients taking into consideration the three critical areas of the co-creation process outlined. 
Our conceptualisation of the value co-creation process suggests that, within the context of the doctor-patient encounter, both actors have their respective value expectations before, during and after the encounter. The findings highlight the different perceptions of value to the focal dyad. An instance is the doctors' consideration of the operational or functional units, and achieving positive outcomes as value as compared to the patients' total experience of the service encounter in addition to 'getting well'. This brings to the fore the emotional aspects of the service delivery which the patient finds critical to the treatment process. This also highlights the importance of the actors' experiences in the consulting room, which can either lead to value creation or destruction.

Therefore, there is the need for service providers or doctors to understand the patient and not just limit their role to the provision of information in relation to reporting symptoms. The dynamics of the doctor-patient encounter is changing as a result of the patient becoming more enlightened and informed. Hence healthcare providers need to understand the changing trends in patient behaviours and incorporate the patients' expectations and goals into their decision goals. However, considering the knowledge conflict between the doctor and the patient, there is a question as to whether or not doctors should always incorporate the demands of the patients in decisions. In order not to compromise the quality of the decision outcome as well as the patient experience, doctors should be tactful in handling such situations by clearly explaining the net effects to the patient. Hence the integration of resources (knowledge and skills) plays a critical role in the co-creation process. 
The findings suggest the need for providers to take a holistic view of service delivery and consider the critical areas of the co-creation process to allow patients an active participatory role. Healthcare as a high participatory service requires patient's active involvement to ensure successful outcomes (Gill et al., 2011; Wilson et al., 2012), hence ineffective co-creation of the service can lead to unproductive outcomes to the detriment of the patient's health.

\section{Limitations and future research}

The healthcare service comprises of different professionals who also interact with the patients and contribute to the overall value that is created by the patient; therefore, focusing on the doctors alone and their encounter with the patients may not present a holistic picture of the patient's experiences. Further research is needed to consider other professionals and service managers in healthcare service delivery. Secondly, the conceptual model in this research may have limitations resulting from the relatively small sample size. However, this model provides useful insights into the concept of value co-creation in the healthcare setting from the dyadic perspective. Future research could employ a quantitative study with a larger sample size to ascertain its applicability and robustness in the healthcare setting. There may also be an opportunity to replicate it in other service contexts.

\section{References}

Aarikka-Stenroos, L. and Jaakkola, E. (2012), "Value co-creation in knowledge intensive business services: a dyadic perspective on the joint problem solving process", Industrial Marketing Management, Vol. 41 No. 1, pp. 15-26. 
Andrews, L., Kiel, G., Drennan, J., Boyle, M.V. and Weerawardena, J. (2007), "Gendered perceptions of experiential value in using web-based retail channels", European Journal of Marketing, Vol. 41 No. 5/6, pp. 640658.

Auh, S., Bell, S.J., McLeod, C.S. and Shih, E. (2007), "Co-production and customer loyalty in financial services", Journal of Retailing, Vol. 83 No. 3, pp. 359-370.

Austin, J.E. and Seitanidi, M.M. (2012), "Collaborative value creation: A review of partnering between nonprofits and businesses: Part I. Value creation spectrum and collaboration stages", Nonprofit and Voluntary Sector Quarterly, Vol. 41 No. 5, pp. 726-758.

Ballantyne, D. and Varey, R.J. (2006), "Creating value-in-use through marketing interaction: the exchange logic of relating, communicating and knowing", Marketing Theory, Vol. 6 No. 3, pp. 335-348.

Bitner, M.J., Booms, B.H. and Tetreault, M.S. (1990), "The service encounter: diagnosing favourable and unfavourable incidents," Journal of Marketing, Vol. 54 No. 1, pp. 71-84.

Blocker, C.P. (2011), "Modelling customer value perceptions in crosscultural business markets", Journal of Business Research, Vol. 64 No. 5, pp. 533-540.

Butterfield, L.D., Borgen, W.A., Amundson, N.E. and Maglio, A.T. (2005), "Fifty years of the critical incident technique: 1954-2004 and beyond", Qualitative Research, Vol. 5 No. 4, pp. 475-497.

Chandler, J.D. and Vargo, S.L. (2011), "Contextualization and value-incontext: how context frames exchange", Marketing Theory, Vol. 11 No. 1, pp. 35-49.

Claramita, M., Utarini, A., Soebono, H., Van Dalen, J. and van der Vleuten, C. (2011), "Doctor-patient communication in a Southeast Asian setting: the conflict between ideal and reality", Advances in Health Sciences Education, Vol. 16 No. 1, pp. 69-80.

Collins, S., Britten, N., Ruusuvuori, J. and Thompson, A. (2007), "Understanding the process of patient participation", in Collins, S., Britten, N., Ruusuvuori, J. and Thompson, A. (Ed.), Patient Participation in Health Care Consultations: Qualitative Perspectives, Open University Press, New York, pp. 3-21.

Cova, B., Dalli, D. and Zwick, D. (2011), "Critical perspectives on consumers' roles as 'producer': broadening the debate on value co-creation in marketing processes", Marketing Theory, Vol. 11 No. 3, pp. 231-241.

Dellande, S., Gilly, M.C. and Graham, J.L. (2004), "Gaining compliance and losing weight: the role of the service provider in health care services", Journal of Marketing, Vol. 68 No. 3, pp. 78-91.

Department of Health (2010), 'Equity and excellence: Liberating the NHS'. White Paper presented to Parliament, available at: 
http://www.dh.gov.uk/en/Publicationsandstatistics/Publications/Publications PolicyAndGuidance/DH_117353 (accessed 13 December 2012).

Donna, L. and Novak, H.T.P. (1997), "A new marketing paradigm for electronic commerce", The Information Society, Vol. 13 No. 1, pp. 43-54.

Dubois, A. and Gadde, L.E. (2002), "Systematic combining: an abductive approach to case research", Journal of Business Research, Vol. 55 No. 7, pp. 553-560.

Echeverri, P. and Skalen, P. (2011), "Co-creation and co-destruction: a practice-theory based study of interactive value formation", Marketing Theory, Vol. 11 No. 3, pp. 325-350.

Edvardsson, B., Tronvoll, B. and Gruber, T. (2011), "Expanding understanding of service exchange and value co-creation: a social construction approach", Journal of the Academy of Marketing Science, Vol. 39 No. 2, pp. 327-339.

Elg, M., Engstrom, J., Witell, L., and Poksinska, B. (2012), "Co-creation and learning in health-care service development", Journal of Service Management, Vol. 23 No. 3, pp. 328-343.

Flanagan, J.C. (1954), "The critical incident technique", Psychological Bulletin, Vol. 51 No. 4, pp. 327-358.

Flint, D.J. (2006), "Innovation, symbolic interaction and customer valuing: thoughts stemming from a service-dominant logic of marketing" Marketing Theory, Vol. 6 No. 3, pp. 349-362.

Flynn, D., Knoedler, M.A., Hess, E.P., Murad, M.H., Erwin, P.J., Montori, V.M., and Thomson, R.G. (2012), "Engaging patients in health care decisions in the emergency department through shared decision-making: A Systematic Review", Academic Emergency Medicine, Vol. 19 No. 8, pp. 959-967.

Gallan, A.S., Jarvis, C.B., Brown, S.W., and Bitner, M.J. (2013), "Customer positivity and participation in services: an empirical test in a health care context”, Journal of the Academy of Marketing Science, Vol. 41 No. 3, pp. 338-356.

Gentile, C., Spiller, N. and Noci, C. (2007), "How to sustain the customer experience: an overview of experience components that co-create value with the customer", European Management Journal, Vol. 25 No. 5, pp. 395410.

Geraerdts, R. (2012), "Customer value creation: a journey in the search of excellence", Industrial Marketing Management, Vol. 41 No. 1, pp. 11-12.

Gill, L., White, L. and Cameron, I.D. (2011), "Service co-creation in community-based aged healthcare", Managing Service Quality, Vol. 21 No. 2, pp.152-177.

Godolphin, W. (2009), "Shared decision-making”, Healthcare Quarterly, Vol. 12, pp. 186-190.

Gremler, D. (2004), "The critical incident technique in service research", Journal of Service Research, Vol. 7 No. 1, pp. 65-89. 
Gronroos, C. (2006), "Adopting a service logic for marketing", Marketing Theory, Vol. 6 No. 3, pp. 317-333.

Gronroos, C. (2011), "Value co-creation in service logic: a critical analysis", Marketing Theory, Vol. 11 No. 3, pp. 279-301.

Gronroos, C. and Voima, P. (2013), "Critical service logic: making sense of value creation and co-creation" Journal of the Academy of Marketing Science, Vol. 41 No. 2, pp. 133-150.

Grove, S.J. and Fisk, R.P. (1997), "The impact of other customers on service experiences: a critical incident examination of "getting along", Journal of Retailing, Vol. 73 No. 1, pp. 63-85.

Gummerus, J. (2013), "Value creation processes and value outcomes in marketing theory Strangers or siblings?" Marketing Theory, Vol. 13 No. 1, pp.19-46.

Gummerus, J. and Pihlstrom, M. (2011), "Context and mobile services' value-in-use", Journal of Retailing and Consumer Services, Vol. 18 No. 6, pp. 521-533.

Gummesson, E. (1998), "Implementation requires a relationship marketing paradigm", Journal of the Academy of Marketing Science, Vol. 26 No. 3, pp. 242-249.

Gummesson, E., Lusch, R.F. and Vargo, S.L. (2010), "Transitioning from service management to service-dominant logic: observations and recommendations", International Journal of Quality and Service Sciences, Vol. 2 No. 1, pp. 8-22.

Hausman, A. (2004), "Modeling the patient-physician service encounter: improving patient outcomes", Journal of the Academy of Marketing Science, Vol. 32 No. 4, pp. 718-739.

Heinonen, K., Strandvik, T., Mickelsson, K.J., Edvardsson, B., Sundstrom, E., and Andersson, P. (2010), "A customer dominant logic of service", Journal of Service Management, Vol. 21 No. 4, pp. 531-548.

Helkkula, A., Kelleher, C. and Pihlstrom, M. (2012), "Characterizing value as an experience: implications for service researchers and managers", Journal of Service Research, Vol. 15 No. 1, pp. 59-75.

Hennig-Thurau, T. (2004), "Customer orientation of service employees: Its impact on customer satisfaction, commitment, and retention", International Journal of Service Industry Management, Vol. 15 No. 5, pp. 460-478.

Higgins, E.T., Vookles, J. and Tykocinski, O. (1992), "Self and health: How "patterns" of self-beliefs predict types of emotional and physical problems", Social Cognition, Vol. 10 No. 1, pp. 125-150.

Holbrook, M.B. (2006a), "Consumption experience, customer value, and subjective personal introspection: an illustrative photographic essay", Journal of Business Research, Vol. 59 No. 6, pp. 714-725.

Holbrook, M.B. (2006b), "ROSEPEKICECIVECI versus CCV: The resourceoperant, skills-exchanging, performance-experiencing, knowledgeinformed, competence-enacting, co-producer-involved, value-emerging, 
customer-interactive view of marketing versus the concept of customer value: 'I can get it for you wholesale', in Lusch, R.F. and Vargo, S.L. (Ed.), The Service Dominant Logic Of Marketing: Dialog, Debate And Directions, New York: M.E. Sharpe, Armonk, pp. 208-223.

Ind, N. and Coates, N. (2013), "The meanings of co-creation", European Business Review, Vol. 25 No. 1, pp. 86-95.

Institute of Medicine (2001), "Crossing the quality chasm: a new health system for the 21st century", Available at: http://www.nap.edu/html/quality_chasm/reportbrief.pdf (Accessed 10 August 2012).

Jaakkola, E., and Alexander, M. (2014), "The role of customer engagement behavior in value co-creation a service system perspective", Journal of Service Research, Available at: http://jsr.sagepub.com/content/early/2014/04/07/1094670514529187.full.pdf +html (Accessed 30 June 2014).

Jaakkola, E. and Halinen, A. (2006), "Problem solving within professional services: evidence from the medical field", International Journal of Service Industry Management, Vol. 17 No. 5, pp. 409-429.

Keatinge, D. (2002), "Versatility and flexibility: attributes of the critical incident technique in nursing research", Nursing and Health Sciences, Vol. 4 No. 1/2, pp. 33-39.

Laing, A., Hogg, G., Fischbacher, M. and Smith, A. (2002), "Managing and Marketing Health Services", Thomson, Cornwall.

Lin, J.S.C. and Hsieh, C.C. (2011), "Modeling service friendship and customer compliance in high-contact service relationships", Journal of Service Management, Vol. 22 No. 5, pp. 607-631.

Mano, H. and Oliver, R.L. (1993), "Assessing the dimensionality and structure of the consumption experience: Evaluation, feeling and satisfaction”, Journal of Consumer Research, Vol. 20 No. 3, pp. 451-466.

Makaoul, G. and Clayman, M.L. (2006), "An integrative model of shared decision making in medical encounters", Patient Education and Counseling, Vol. 60 No. 3, pp. 301-312.

Mathwick, C., Malhotra, N. and Rigdon, E. (2001), "Experiential value: Conceptualization, measurement and application in the catalog and Internet shopping environment", Journal of Retailing, Vol. 77 No. 1, pp. 39-56.

Maxwell, J.A. (1992), "Understanding and Validity in Qualitative Research", Harvard Educational Review, Vol. 62 No. 3, pp. 279-300.

McColl-Kennedy, J.R., Vargo, S.L., Dagger, T.S., Jillian C. Sweeney, J.C. and van Kasteren, Y. (2012), "Health care customer value co-creation practice styles", Journal of Service Research, Vol. 15 No. 4, pp. 370-389.

McKnight, D.H., Cummings, L.L. and Chervany, N.L. (1998), "Initial trust formation in new organizational relationships", Academy of Management Review, Vol. 23 No. 3, pp. 473-490. 
Nambisan, P. and Nambisan, S. (2009), "Models of consumer value cocreation in health care", Health Care Management Review, Vol. 34 No. 4, pp. 344-354.

Nettleton, S. (1995), "The sociology of health and illness", Polity Press, Cambridge, MA.

Payne, A.F., Storbacka, K. and Frow, P. (2008), "Managing the co-creation of value", Journal of the Academy of Marketing Science, Vol. 36 No. 1, pp.83-96.

Perrault, J.W.D. and Leigh, L.E. (1989), "Reliability of Nominal Data Based on Qualitative Judgments $\square$ ", Journal of Marketing Research, Vol. 26 No. 2, pp. 135-148.

Ple, L. and Caceres, C.R. (2010), "Not always co-creation: introducing interactional co-destruction of value in service-dominant logic", Journal of Services Marketing, Vol. 24 No. 6, pp. 430-437.

Porter, M.E. (2009), "A strategy for health care reform - toward a valuebased system", The New England Journal of Medicine, Vol. 361 No. 2, pp. 109-112.

Porter, M.E. (2010), "What is value in health care?", The New England Journal of Medicine, Vol. 363 No. 26, pp. 2477-2481.

Prahalad, C.K. and Ramaswamy, V. (2004), "Co-creating unique value with customers", Strategy and Leadership, Vol. 32 No. 3, pp.4-9.

Ranganathan, S.K., Madupu, V., Sen, S., and Brooks, J.R. (2013), "Affective and cognitive antecedents of customer loyalty towards e-mail service providers", Journal of Services Marketing, Vol. 27 No. 3, pp. 195206.

Roos, I. (2002), "Methods of investigating critical incidents: a comparative review", Journal of Service Research, Vol. 4 No. 3, pp. 193-204.

Saarijarvi, H., Kannan, P.K. and Kuusela, H. (2013), "Value co-creation: theoretical approaches and practical implications", European Business Review, Vol. 25 No. 1, pp. 6-19.

Sanchez-Fernandez, R. and Iniesta-Bonillo, M.A. (2007), "The concept of perceived value: a systematic review of the research", Marketing Theory, Vol. 7 No. 4, pp. 427-51.

Sandstrom, S., Edvardsson, B., Kristensson, P., and Magnusson, P. (2008), "Value in use through service experience", Managing Service Quality, Vol. 18 No. 2, pp. 112-126.

Schau, H.J., Muniz Jr., A.M. and Arnould, E.J. (2009), "How brand community practices create value", Journal of Marketing, Vol. 73 No. 5, pp. 30-51.

Spena, T.R., Carida, A., Colurcio, M. and Melia, M. (2012), "Store experience and co-creation: the case of temporary shop", International Journal of Retail \& Distribution Management, Vol. 40 No. 1, pp. 21-40. 
Taylor, K. (2009), "Paternalism, participation and partnership - the evolution of patient centeredness in the consultation", Patient Education and Counseling, Vol. 74 No. 2, pp. 150-155.

Thompson, A. (2007), "The meaning of patient involvement and participation in healthcare consultations: a taxanomy", in Collins, S., Britten, N., Ruusuvuori, J. and Thompson, A. (Ed.), Patient Participation in Health Care Consultations: Qualitative Perspectives, Open University Press, New York, pp. 43-64.

Tsai, S. (2005), "Integrated marketing as management of holistic consumer experience", Business Horizons, Vol. 48 No. 5, pp. 431-441.

Vargo, S.L. and Lusch, R.F. (2004), "Evolving to a new dominant logic for marketing", Journal of Marketing, Vol. 68 No. 1, pp.1-17.

Vargo, S.L and Lusch, R.F. (2008), "Service-dominant logic: continuing the evolution", Journal of the Academic Marketing Science, Vol. 36 No. 1, pp.110.

Vargo, S.L., Maglio, P.P and Akaka, M.A. (2008), "On value and value cocreation: a service systems and service logic perspective", European Management Journal, Vol. 26 No. 3, pp. 145-152.

Voima, P., Heinonen, K. and Strandvik, T. (2010), "Exploring customer value formation-a customer dominant logic perspective", Working paper, No. 552, Publications of Hanken School of Economics, Helsinki, Finland.

Whittemore, R., Chase, S.K. and Mandle, C.L. (2001), "Validity in qualitative research", Qualitative Health Research, Vol. 11 No. 4, pp. 522537.

Wilson, A., Zeithaml, V.A., Bitner, M.J. and Gremler, D.D. (2012), "Services marketing: integrating customer focus across the firm", McGraw-Hill, Berkshire.

Wikstrom, S. (1996), "The customer as co-producer", European Journal of Marketing, Vol. 30 No. 4, pp. 6-19.

Young, T.P. and McClean, S.I. (2008), "A critical look at lean thinking in healthcare", Quality and Safety in Health Care, Vol. 17 No. 5, pp. 382-386.

Zainuddin, N., Previte, J. and Russell-Bennett, R. (2011), "A social marketing approach to value creation in a well-women's health service", Journal of Marketing Management, Vol. 27 No. 3-4, pp. 361-385.

Zwick, D., Bonsu, S.K., and Darmody, A. (2008), "Putting consumers to work: co-creation and new marketing govern-mentality", Journal of Consumer Culture, Vol. 8 No. 2, pp. 163-196. 
Fig. 1. Model of Doctor-Patient dyadic value co-creation process

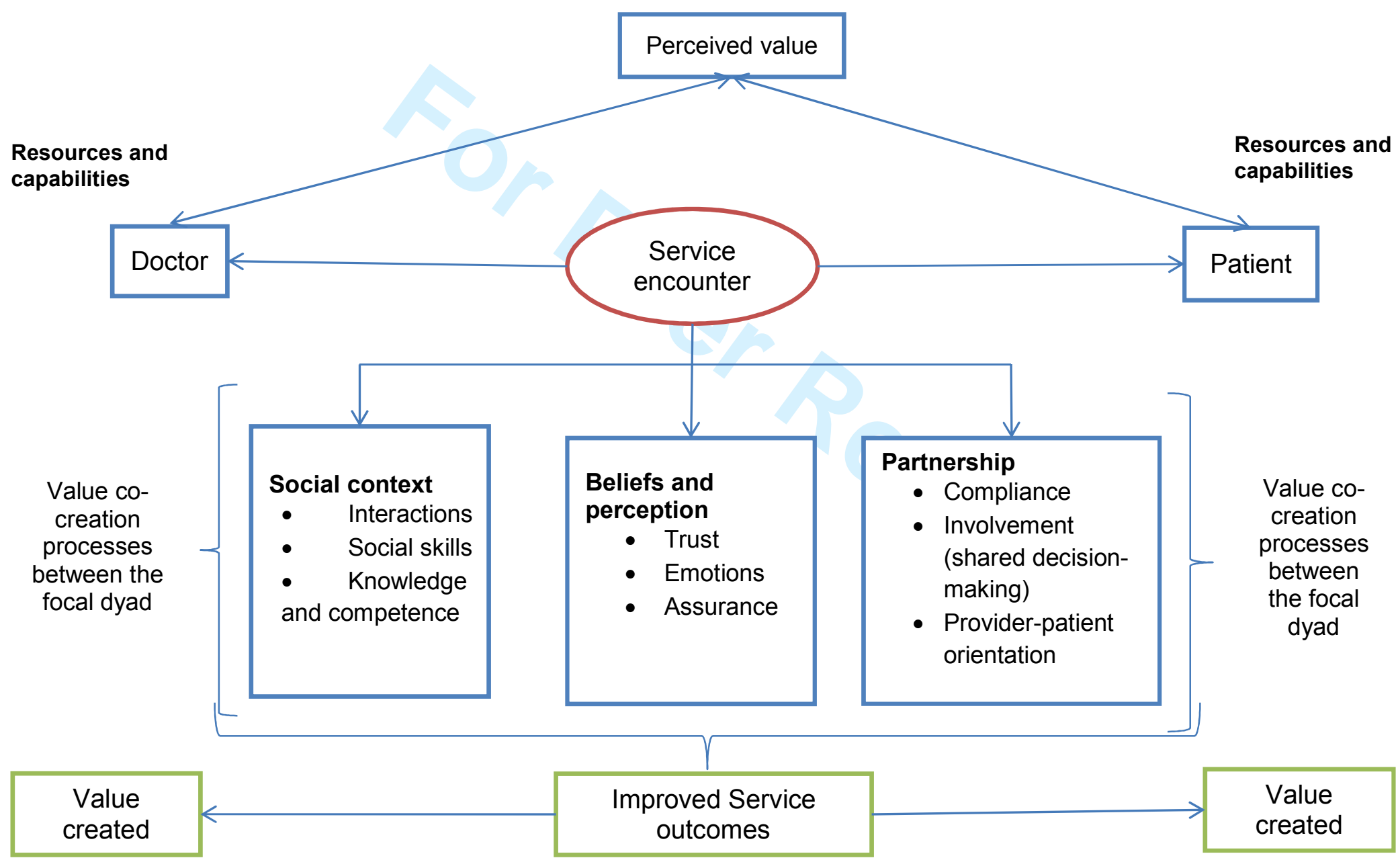

Source: Authors model 


\section{Table 1 :}

Main and subcategories of the value co-creating processes of the focal dyad

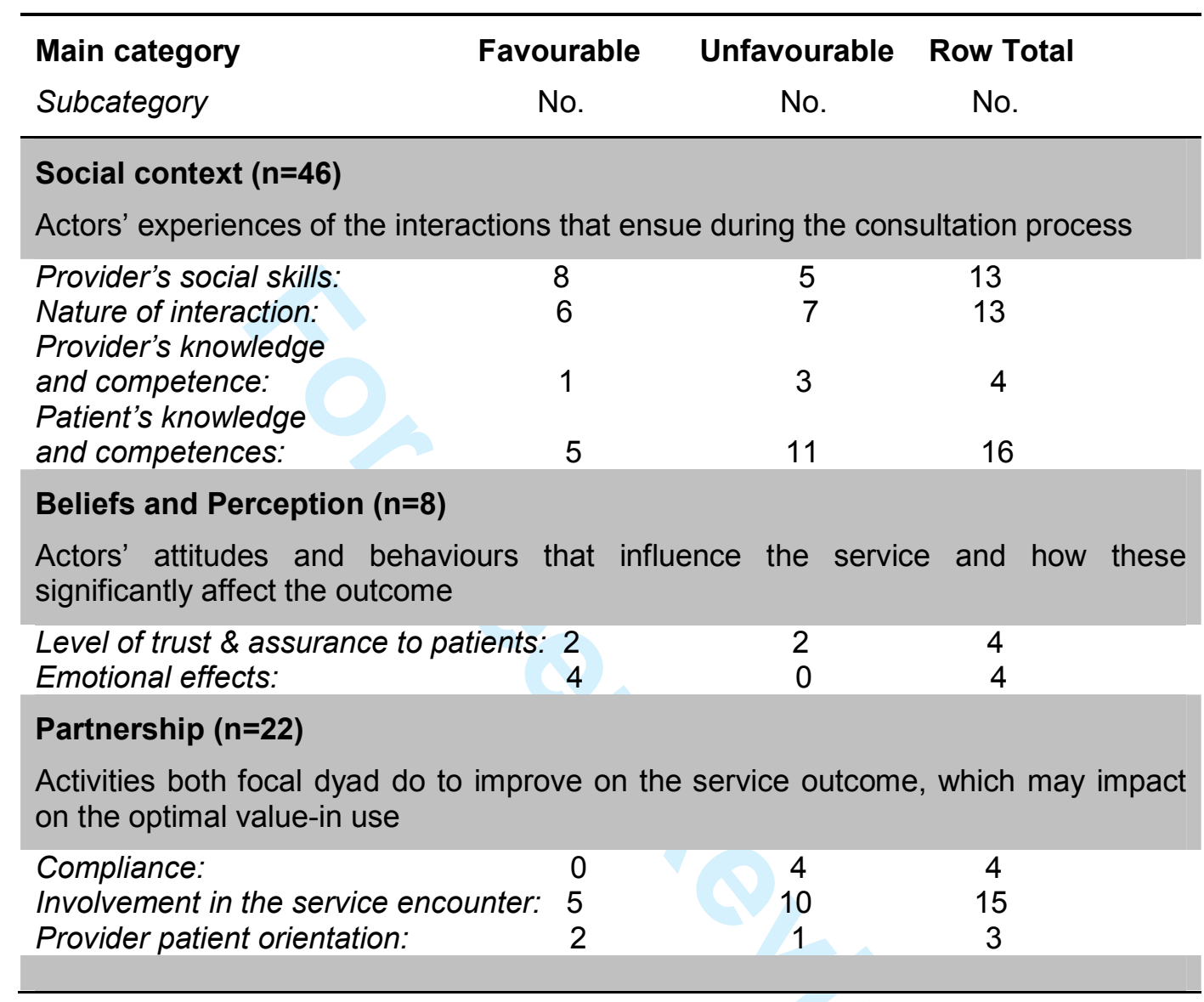

$n$ - number of critical incidents identified 